\title{
Associação de peeling orgânico com sangria para rejuvenescimento
}

\author{
Daniela Oliveira Lopes ${ }^{1}$ \\ daniela.lopezz@hotmail.com \\ Dr. Fabiano de Abreu Agrela Rodrigues ${ }^{2}$ \\ deabreu.fabiano@gmail.com
}

\section{RESUMO}

O presente estudo versa sobre o uso do peeling orgânico intercalado com mescla de sangria para rejuvenescimento, a fim de que se consiga uma eficácia no tratamento de rejuvenescimento em região diversificada.

Palavras-chaves: peeling orgânico, sangria, eficácia, Rejuvenescimento, retração tecidual, regeneração de tecidos.

\footnotetext{
${ }^{1}$ Especialista em estética e cosmetologia intradérmicas Instituição de atuação atual: Sociedade Brasileira de Estética e Cosmetologia Endereço completo: Rua Tabapua, 145 - 11 andar, Bairro Itaim Bibi São Paulo SP CEP: 043533-010 BRASIL

${ }^{2} \mathrm{PhD}$, neurocientista, neuropsicólogo, mestre em psicanálise com pós graduação em antropologia, jornalista e especialista em nutrição clínica.

CPAH- Centro de Pesquisas e Análises Heráclito Rua Costinha, n95 4550-023 Sobrado e Bairros Aveiro, Castelo de Paiva PORTUGAL
} 


\title{
Association of organic peeling with sangria \\ for rejuvenation
}

\begin{abstract}
The present study deals with the use of organic peeling interspersed with a blend of bleed for rejuvenation, in order to achieve an efficacy in the treatment of rejuvenation in a diversified region.
\end{abstract}

Keywords: organic peeling, bleeding, efficacy, rejuvenation, tissue retraction, tissue regeneration.

Artículo recibido: 02 enero 2022 Aceptado para publicación: 28 enero 2022 Correspondencia: daniela.lopezz@hotmail.com Conflictos de Interés: Ninguna que declarar 


\section{INTRODUÇÃO}

Diariamente a pele é notada como uma questão essencial da estética representada como o símbolo da juventude, do senso cronológico, do cuidadoe muitas vezes até como símbolo da sabedoria por meios de suas rugas aparentes. De acordo com Barbosa (2011, apud BARCELOS; FERREIRA, 2018), a pele até pode parecer um órgão simples, pois ela tem uma complexa e extensa estrutura que deve ser tratada com procedimentos, cuidados e aplicações para que os seus componentes não venham perder as suas propriedades.

A pele é composta por 3 componentes e este contém cada uma a suaespecificidade, que são a Epiderme, Derme e Hipoderme, onde: Epiderme é de origem ectodérmica e é responsável pela impermeabilização da pele e produz a queratina, já a Derme é de origem mesodérmica e situam-se os vasos, nervos, músculos eretores dos pelos e Hipoderme é uma camada que é responsável pelo deslizamento das estruturas subjacentes cuja poderá ter camadas formadas por células gordurosas. Sousa et al (2015, apud BARCELOS; FERREIRA, 2018). De acordo com Batistela, Chorilli e Leonardi (2007) (apud BARCELOS; FERREIRA, 2018), para manter o sistema em equilíbrio a pele possui algumas funções como proteção, nutrição, queratogênese, pigmentação, transpiração, perspiração, termorregulação, defesa e absorção.

Segundo Barcelos e Ferreira (2018), um dos maiores problemas no campo da estética é o envelhecimento. Sendo ele Nardin (1999, apud BARCELOS; FERREIRA, 2018), este envelhecimento cutâneo é intrínseco e atrófico o que acaba resultando na perda da elasticidade, o que causa atrofiação epidérmica, assim aumentando as linhas de expressão, causada pelo achatamento na junção dermo-epidérmica na camada basal e reticular, e faz com que a atividade metabólica se torne mais lenta. Zanluchi (2007), ainda ressalta que o envelhecimento extrínseco se dá pelo envelhecimento a exposição dos raios UV, assim causando flacidez, rugas o engrossamento da pele e a pigmentação irregular (apud BARCELOS;FERREIRA, 2018).

Dentre essas adversidades, existe uma diversidade de tratamentos que possam ser utilizados, como o uso da terapia de peeling químico, que é uma quimioesfoliação com aplicação de um ou mais agentes com propriedades esfoliantes como ácidos, e que resulta na destruição de partes da epiderme e/ou da derme, posteriormente ocorre uma regeneração dos tecidos dérmicos e epidérmicos. Kede (2015, apud BARCELOS 
;FERREIRA, 2018). Visto toda movimentação em torno desse tema, foi criado um protocolo na era moderna dos peelings orgânicos intercalando com mescla de técnicas causadoras de sangria. Foi ajustado dois agentes superficiais para produzirem um peeling de média profundidade. Utilizando outra técnica de combinação de mescla intradérmica, combinado ou isolado. Para realização desta pesquisa teve-se como motivação à afinidade pela estética facial e fascínio com relação aos benefícios que os procedimentos estéticos fornecem à pele, independente da idade do paciente.

Aponta Nascimento (2015), que a definição do envelhecimento se dá por meio da diminuição da eficiência da homeostase, devido a sobrecarga funcional do organismo, e essas mudanças ocorrem durante a maturidade humana, que compromete os estímulos aos poucos, como resposta do corpo e manutenção do mesmo (apud BARCELOS; FERREIRA, 2018).

Afirma Barcelos e Ferreira (2018), que o objetivo da pesquisa é relatar os satisfatórios resultados em relação ao rejuvenescimento da pele com o uso de peeling químico de alfa hidroxiácidos, suas aplicações, reações e concentrações, mostrando a forma adequada de aplicações e com grande importância na anamnese.

\section{ESCALA DE GRAU DE ENVELHECIMENTO}

Para auxiliar na decisão do tratamento para cada indivíduo e para entender a pele envelhecida, foram criadas classificações clínicas do envelhecimento facial. Segundo uma classificação do envelhecimento elaborado por Richard Glogau, a mesma pode variar do tipo I ao tipo IV, e é usada como um dos principais critérios para a escolha da profundidade dos peelings. Pereira e Mejia (2016, apud BARCELOS; FERREIRA, 2018). Depreendemos de Souza et al. (2007, apud BARCELOS; FERREIRA, 2018), que com essa classificação a pele pode ser agrupada em IV graus de acordo com os sinais que apresenta, conforme a Tabela 1 .

\section{Tabela 1.}




\begin{tabular}{c|l}
\hline Grau I & $\begin{array}{l}\text { Mínimas rugas, fotoenvelhecimento inicial, alteração suave na } \\
\text { pigmentação, ausência de queratoses ou lentigos senis; acomete pessoas } \\
\text { dos } 20 \text { aos } 30 \text { anos que geralmente não necessitam de maquiagem. }\end{array}$ \\
\hline Grau II & $\begin{array}{l}\text { A pele permanece lisa na ausência de movimentos, mas durante a } \\
\text { movimentação (sorriso, franzir a testa etc.) as rugas aparecem, presença } \\
\text { de lentigos senis e telangectasias iniciais, mas não possui queratoses } \\
\text { visíveis; acomete pessoas dos } 30 \text { aos } 40 \text { anos que necessitam de uma } \\
\text { maquiagem leve. }\end{array}$ \\
\hline Grau III & $\begin{array}{l}\text { Rugas visíveis mesmo na ausência de movimentação, presença de lentigos } \\
\text { senis, telangiectasias e queratoses solares; acomete pessoas acima dos 50 } \\
\text { anos que necessitam de maquiagem constantemente. }\end{array}$ \\
\hline Grau IV & $\begin{array}{l}\text { Rugas generalizadas, diminuição da espessura da epiderme, pele com } \\
\text { coloração amarelo-acinzentado (pelo aumento da espessura da camada } \\
\text { córnea), maior tendência a câncer de pele; acomete pessoas acima dos } 60 \\
\text { anos que a maquiagem não deve ser utilizada porque resseca e fragmenta. }\end{array}$ \\
\hline
\end{tabular}

Fonte: Adaptado de Souza et al. (2007, apud BARCELOS; FERREIRA, 2018, p.6)

\section{CLASSIFICAÇÃO DOS PEELINGS ORGÂNICOS}

A escolha da técnica específica a ser usada foi obtida através do conhecimento da profundidade da lesão. Sendo assim o peeling orgânico como atinge apenas a epiderme, os melhores resultados foram obtidos com aplicações seriadas, realizadas em intervalos curto. Induzindo a descamação, com uma aceleração consequente do ciclo celular.

Essas soluções removeram a camada superficial do estrato córneo, gerando uma pele de textura mais suave e pigmentada de modo mais homogêneo. Melhora na textura da pele, são coadjuvantes no tratamento da acne, clareiam manchas e atenuam rugas finas, além de estimular a renovação de colágeno. Provocando uma descamação uniforme. São indicados para ceratoses (lesões pré-cancerosas) e rugas mais pronunciadas.

A recuperação pode durar até um mês. Apresentam resultados significativos, com renovação importante da pele e diminuição de rugas profundas, como aquelas ao redor da boca e dos olhos.

\subsection{Poli Hidroxiácidos}

Os poli-hidroxiácidos (PHA) fazem parte de um grupo de substâncias utilizadas nessas 
categorias de peeling, são ativos derivados do açúcar e insumos orgânicos. O Peeling Orgânico são produtos de utilização em peelings superficiais e médios, indicados para rugas finas, médias, lesões actínicas, melasma, efélides, acne, discromias, peles rugosas, hiperpigmentação pós-inflamatória hiper queratinização, fotoenvelhecimento e queratoses.

Estudos clínicos demonstram que o uso tópico do peeling orgânico auxilia no reparo e proporciona melhoria de rugas finas, asperezas e reverte os danos provocados pelo sol. Resultados histológicos do tratamento com peeling orgânico, incluem redução na espessura do extrato córneo, diferenciação celular mais organizada, dispersão dos grânulos de melanina, aumento da espessura da derme papilar, da síntese de colágeno pelo estímulo de fibroblastos, dos níveis de ácido hialurônico e de fibras elásticas.

Age no envelhecimento, promovendo melhoras em relação ao tratamento de rugas superficiais, médias e profundas, manchas senis, flacidez de pele, pele seca, entre outras. É indicado para todos os tipos de pele e em qualquer região do corpo. Inclusive vantajoso para o rejuvenescimento para peles mais morenas.

\subsection{Considerações Finais Do Peeling Orgânico}

Após a análise dos estudos e de toda revisão clínica sobre o tratamento foi possível identificar que o uso dos poli-hidroxiácidos, nas formulações de peelings orgânicos atuam de maneira rejuvenescedora, melhorando o aspecto e aparência da pele deixando-a mais macia e hidratada, fazendo com que haja uma redução da coesão entre as células facilitando o processo de renovação celular. Foi possível também observar o clareamento das manchas senis e renovação celular em maior escala, proporcionando a pele um aspecto mais uniforme e liso.

No entanto pode observar no estudo que para que se tenha resultados satisfatórios deve atentar-se às mesclas de técnicas de sangria, observando-se maiores concentrações de estímulo dos fibroblastos comparado ao protocolo do peeling orgânico sem utilização das mesclas.

\section{MESCLAS DE TÉCNICAS DE SANGRIA}

A Sangria é uma técnica antiga, usada inicialmente na antiguidade com ventosaterapia e acupuntura. Com o avanço das técnicas em estética, utilizei uma mescla de microagulhamento 2,00 mm, dermapen, ventosaterapia e eletropuntura, em uma junção com aplicação tópica de Vit.E, A, DMAE, Colágeno e Ácido Hialurônico. 
As mesclas de sangria promovem um efetivo transporte dessas substâncias diretamente para a área a ser tratada, vários estudos descrevem a técnica, porém, não existe um padrão metodológico entre eles. Em comum, é descrito que a sangria favorece na circulação sanguinea, aumento da oxigenação períferica.

\section{Herreros (2011, apud SILVA, 2018, p. 16), ressalta em seus estudos que:}

Quanto à profundidade da agulha, esta não pode penetrar mais de 4mm, por isso a indicação de aplicação com agulha de Lebel, que possui o bisel com 4mm de comprimento. Quanto à técnica de aplicação, a mesoterapia pode ser dividida em intraepidérmica, papular, Nappage ou ponto a ponto.

A técnica de sangria consiste em colocar pequenas quantidades do medicamento na epiderme. É um procedimento dolorido, simples e com sangramento. É indicado para pacientes que necessitam acelerar o processo de fibroblastos, circulação periférica, rejuvenescendo e regenerando o tecido.

A técnica de sangria é útil para tratar rugas e a alopecia que consiste em injetar o medicamento na junção epidérmica e é a técnica usada para no microagulhamento e dermapen.

\section{INDICAÇÕES}

A Sangria é empregada para diversos fins e de acordos com a região de aplicação utilizados. $\mathrm{Na}$ literatura e nas aplicações faciais são evidenciados resultados de redução de várias disfunções estéticas. Na estética facial é indicado para redução de manchas, redução da flacidez e melhoras no tônus. Sendo assim indicada para o rejuvenescimento do tecido. Em estudo realizado na pesquisa clínica e com dois pacientes com idades com 35 e 50 anos, ocorreu a efetividade da técnica de sangria, o que resultou na melhora da aparência clínica da pele nas diferentes faixas etárias, com a restauração da textura juvenil e saúde da pele. Porém, o estudo demonstra que esses resultados não são permanentes e tendem após um tempo diminuir, daí a necessidade que as aplicações sejam em média a cada 6 a 8 meses após a data da última aplicação.

\subsection{Contra-Indicações e Complicações}

Mesmo que a sangria é uma técnica minimamente invasiva e segura, alguns efeitos vem sendo reportados sobre as complicações, que pode ocorrer como efeito rebote em discromias, minúsculos coágulos “ sangue pisado" além de marcas de arranhão, todos 
esses efeitos são temporários. A aplicação é contra-indicada para mulheres grávidas ou em fase de amamentação, portadores de diabetes, histórico de distúrbios emorrágicos, história de ataque súbito, fenômenos tromboembólicos, pessoas em tratamento com medicações antiarrítmicas, aspirina, warfarina, heparina etc., doença cardíaca grave, doença renal ou qualquer outra doença sistêmica crônica grave.

\section{ATIVOS UTILIZADOS NO ESTUDO PARA REJUVENESCIMENTO FACIAL}

Levando em consideração os procedimentos cosméticos não cirúrgicos, há bons resultados, pois utilizam técnicas não invasivas, simples, não traumáticas. A Técnica de Sangria estética, utiliza mesclas nutritiva ou hidratante, através das técnicas de sangria que melhora o brilho, a hidratação da pele o tônus e suaviza rugas superficiais.

Não há como padronizar as mesclas de ativos para uso em técnicas de Sangria, é necessário o estudo minucioso e anamnese de caso a caso. Existem uma mescla prontas para cada distrofia estética, porem recomenda-se que a formula seja manipulada para cada paciente, para atender as particularidades das distrofias e do fotoenvelhecimento, seguindo os mecanismos de ação dos fármacos (SBBME, 2016, apud SILVA, 2018).

Mas em se tratando de técnicas de Sangria é necessário utilizar mesclas que tenham o objetivo de retrair, regenerar e ativar o colágeno naquele tecido. Neste caso não é possível seguir um padrão de mesclas prontas conforme cita SBBME, 2016, apud SILVA,2018). Com base no entendimento atual dos mecanismos de envelhecimento na pele, um dos focos no desenvolvimento de mesclas para a sangria é a identificação de ativos que podem melhorar (ou ajudar a manter) a função dos fibroblastos e melhorar a biossíntese dos componentes da matriz extracelular.

O AH é uma glicosaminoglicana não sulfatada é essencial na matriz extracelular e uma forte rede junto as proteoglicanas. Esta retém água que são essenciais pra o tônus da pele e para a elasticidade adequada (ARDIZZONI et al, 2011; BAUMANN, 2007; GIRISH; KEMPARAJU, 2007, apud SILVA, 2018). O ácido hialurônico ajuda a pele a permanecer hidratada, através da capacidade de acumular e reter 1000 vezes seu peso em água, possui propriedades antifúngicas, antibacteriana, antioxidantes e anti-inflamatória (ARDIZZONI et al, 2011; BAUMANN, 2007, apud SILVA, 2018).

O tratamento com sangria é realizado com sessões semanais, por um período de 2 a 3 semanas e após este período é realizado manutenções mensais, utilizando a técnica de Sangria dermática e agulhamento. As vitaminas utilizadas para compor as mesclas 
possuem funções especificas, por isso, a necessidade em avaliar o nível de queda flácida do tecido, rugosidade e percentual entre rugas estáticas e dinâmicas.

Afirmam Tosti e Padova (2007), que "a vitamina A regula a renovação da epiderme e atua na flexibilidade da pele; ajuda na cura e corrige parcialmente a atrofia da derme; importante na regulação do tunover, queratinização e reparação dos queratinócitos" (apud SILVA, 2018).

Já vitamina $\mathrm{C}$ estimula a síntese de colágeno, é um importante antioxidante que acelera a síntese de DNA e inibe a melanina, reduzindo a hiperpigmentação junto à vitamina $E$, que é um forte antioxidante devido à sua atividade anti-radical livre, controla a regeneração fisiológica da pele e inicia os processos de reparação em caso de danos na pele (TOSTI; PADOVA, 2007, apud SILVA, 2018, p. 20).

O dimetilaminoetanol (DMAE) é muito comum e usado para o antienvelhecimento. Seu princípio é atuar na junção neuromuscular como precursor de acetilcolina, que é um neurotransmissor que atua na contração muscular, resultando no aumento do tônus global da pele. Porém é contraindicado o uso de toxina botulínica em conjunto, pois reduz a sua eficácia (TOSTI; PADOVA, 2007, apud SILVA, 2018).

A timomodulina é extraída da glândula Timo e aumenta os linfócitos T, as células CD3, CD4 e CD8, que possui funções de regulação dos níveis de imunoglobilinas A e G e neurotróficas. É eficaz na redução de linhas de expressão em pacientes fumantes, na limpeza da pele com agentes poluentes nocivos como a fumaça, assim ajudando a reverter o fotoenvelhecimento (TOSTI; PADOVA, 2007, apud SILVA, 2018).

\section{CONSIDERAÇÕES FINAIS DA SANGRIA}

Neste estudo comprova-se a efetividade da técnica de sangria, para tratamento em diversas áreas do corpo, em especial a área facial, apontando uma gama de ativos que, individualmente ou na forma de melanges, atuam no rejuvenescimento. A escolha desses ativos é o ponto chave do sucesso do tratamento, pois deve ser realizada de forma individual, levando em consideração as características e particularidades de cada paciente assim como suas contra-indicações.

Os fibroblastos, por serem as principais células envolvidas no rejuvenescimento, são alvos dos ativos que visam desde fornecer substratos para a formação de substâncias até 
promover um ambiente propício a esta formação. Embora a mesoterapia seja bastante eficaz, o envelhecimento é um processo contínuo, devendo também o tratamento ser feito de forma contínua para que os efeitos positivos sejam mantidos. Apesar de não existir um consenso entre a metodologia da técnica, em geral os estudos descrevem aplicações inicialmente semanais até que os resultados sejam observados e citam que deve ser feita uma manutenção, geralmente mensal, do tratamento. Além disso, a foto proteção é fundamental, já que boa parte dos efeitos do envelhecimento são mediados pela radiação solar.

Ainda existe uma carência no que diz respeito a estudos que comprovem e eficácia e segurança dos ativos, principalmente quando utilizados em conjunto. A comprovação científica é importante para garantir uma aplicação segura e eficaz e consequente satisfação do paciente.

\section{TESTES E RESULTADOS}

O Envelhecimento tecidual e discromias, conforme Figura 1, foi atribuída principalmente por hiperpigmentação; exposição excessiva solar; acompanhada de ptose.

Figura 1 - Pacientes Voluntários $n^{\circ} 1$ e 2

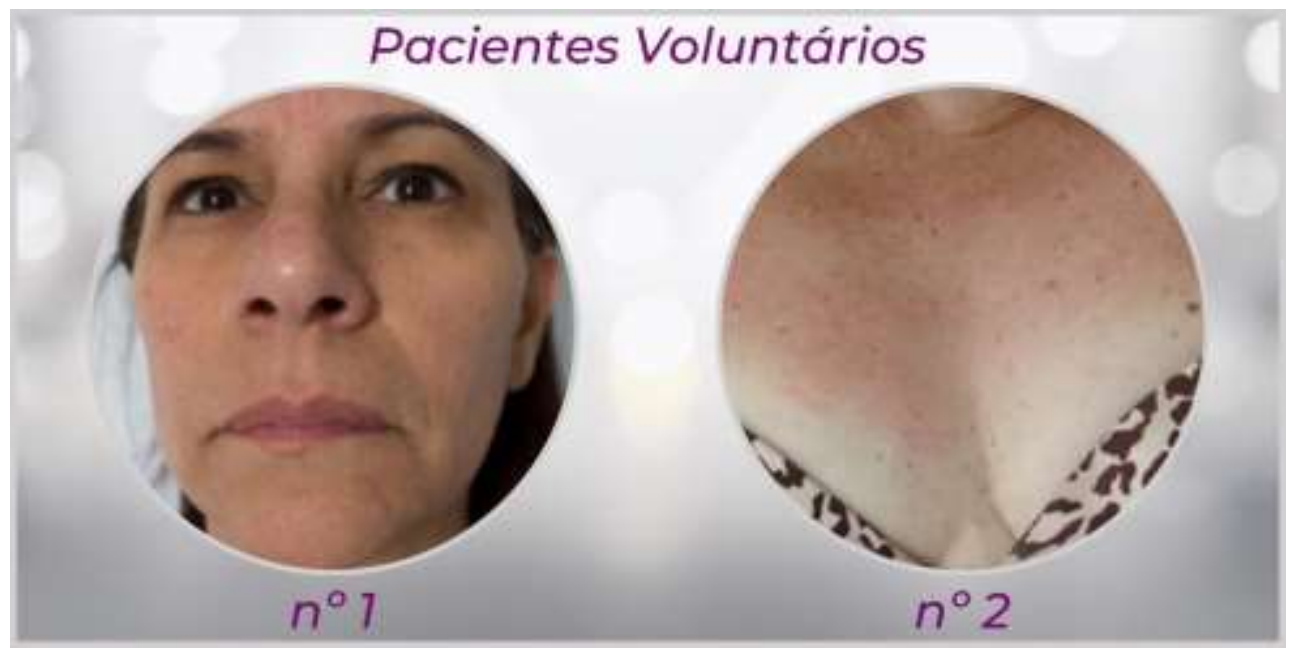

Fonte: da autora (2020).

As queixas dos pacientes, vide Figura 1 são: envelhecimento tecidual, ptose e discromias.

\section{METODOLOGIA}

O estudo de caso foi desenvolvido como uma pesquisa do tipo exploratória e descritiva com abordagem qualitativa e intervenção controlada em 2 voluntários que apresentam envelhecimento na região facial, colo, mãos e fizeram uso de protocolo associado ao 
tratamento clínico e home care com A.Hialurônico, contendo ativos iguais aos utilizados na sangria. Os voluntários foram acompanhadas durante 30 dias e tiveram seus resultados monitorados.

\subsection{Local De Estudo}

A seleção dos voluntários e os encontros foram realizados na clínica Studio 2E, na cidade Mairiporã, São Paulo, SP.

Foram selecionados 2 voluntários que possuem envelhecimento tecidual, ptose e discromias, vide Figura 1.

\subsection{Critérios Éticos Em Pesquisa}

Logo após o convite, todos os voluntários receberam explicação detalhada sobre o estudo, seguida da leitura e assinatura do Termo de Ciência e foram asseguradas do sigilo de sua identidade. Uma cópia do Termo de Ciência foi entregue aos voluntários e outra ficou arquivada com a pesquisadora, conforme Anexo A.

\section{PROCEDIMENTO}

Inicialmente a pesquisadora avaliou o nível de envelhecimento dos voluntários e aplicou o questionário de avaliação do voluntário, conforme Anexo B, para registros dos dados pessoais e demais perguntas necessárias para prosseguir o estudo. Foram obtidas fotografias padronizadas da região a ser tratada, utilizando a câmera digital do Celular Samsung Moto Z2 Play.

Antes de dar início ao protocolo, foi realizado o teste de sensibilidade aos ativos cosméticos (peeling orgânico) a serem utilizados tanto para o tratamento clínico como home care.

Os voluntários foram orientados a aplicar atrás da orelha uma pequena quantidade de cada produto no dia anterior ao início do estudo e no dia seguinte foram questionadas sobre o surgimento de reação dérmica de irritação; eritema, pápulas; vesículas e sobre a intensidade da reação quando esta se apresentasse, pontuando de 0 a 7. Somente com o resultado negativo passaram a receber clinicamente, por 5 sessões, aplicação do peeling orgânico, mesclas tópicas de Vit.A, E, DMAE, A.Hialurônico na junção com as técnicas de microagulhamento a $2 \mathrm{~mm}$, dermapen, ventosaterapia e eletropuntura.

\subsection{Protocolos de Tratamento da Pesquisa}

O protocolo clínico iniciou com a higienização com sabonete líquido de extrato vegetal, e remoção com algodão embebido em água seguido de secagem suave com papel toalha. A aplicação do peeling orgânico, foi efetivada em movimentos circulares suaves por 3 
minutos, seguido de um cataplasma por 10 minutos. Após esse período o produto removido com gaze embebido em água e secagem suave e aplicado a técnica de sangria com a mescla.

Em casa, os voluntários utilizaram sabonete líquido de extrato vegetal para a higienização, Serum Vitamina E, A.H e FPS 30 respectivamente. No período do estudo nenhum outro produto cosmético foi utilizado. As formulações foram adquiridas em uma farmácia de manipulação Victalab para as aplicações em junção com a técnica de sangria e Organic Peel para o peeling e home care.

As voluntárias foram acompanhadas semanalmente em horários pré agendados, durante cinco semanas, totalizando 5 avaliações, com um tempo de procedimento de 50 minutos. A avaliação dos resultados se deu de forma visual a partir da comparação das fotografias do início e após o término das 5 semanas de tratamento e pela resposta a um questionário de satisfação, conforme Anexo C.

\section{RESULTADOS E DISCUSSÃO}

Todos os participantes abordados se encaixaram nos critérios de inclusão do estudo; aceitaram o uso único deste protocolo no período do estudo; aderiram ao tratamento conforme o protocolo proposto, não recusaram assinar o Termo de Ciência; não apresentaram sensibilidade ou irritação no teste prévio ao produto; as mulheres não estavam grávidas ou amamentando; não possuíam doença de pele diagnosticada; distúrbios mentais; epilepsia; cardiopatias; portadoras de marca passo e afecções cutâneas.

O estudo contou com 2 voluntários, com idade variando de 35 a 50 anos, residentes no município de Mairiporã. O estudo aconteceu entre os meses de maio a junho de 2019. Em análise as respostas obtidas do questionário,100\% dos voluntários não relataram antecedentes alérgicos ou doença crônica.

O acompanhamento visual dos resultados, estão conforme Figura 2, 3 e 4.

Tratamento facial para rejuvenescimento do tecido da paciente 1 , realizado em cinco sessões, conforme Figura 2.

Figura 2 - Antes e depois do tratamento facial para rejuvenescimento do tecido da paciente $n^{\circ} 1$ 


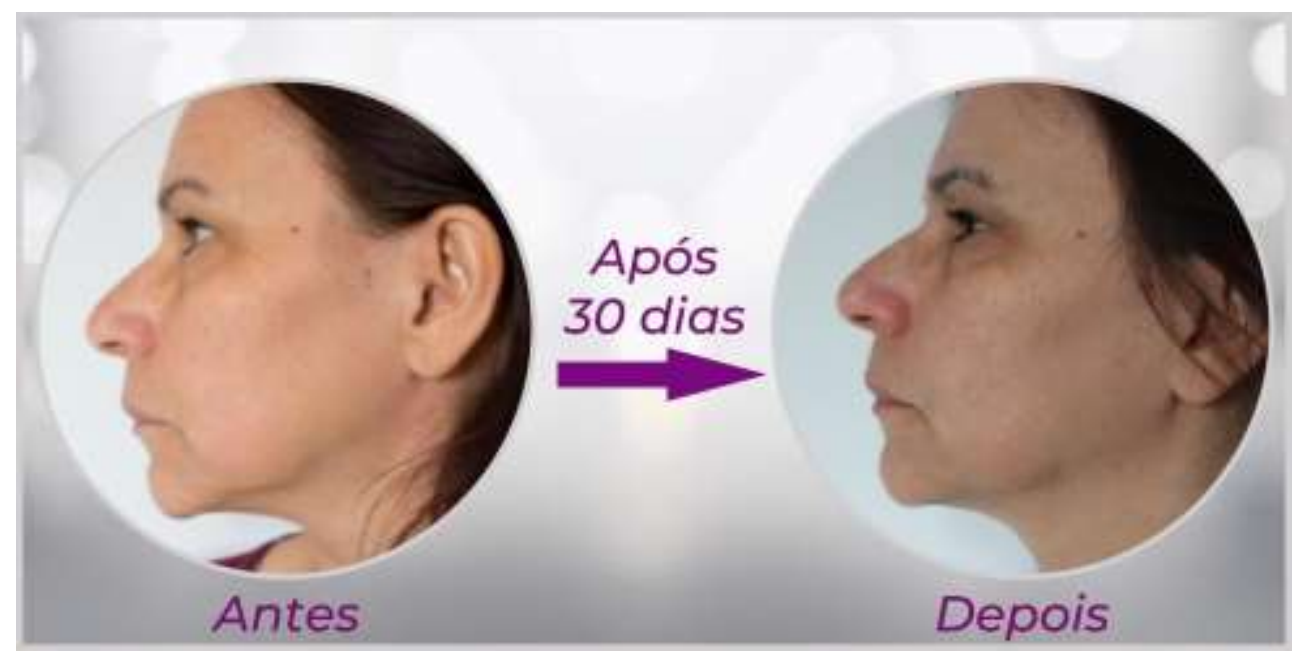

Fonte: da autora (2020).

\subsection{Protocolo: Peeling Orgânico}

Tratamento facial para clareamento das discromias e suavização das rugas do colo, da paciente $n^{\circ} 2$, realizado em três sessões, conforme Figura 3.

Figura 3 - Antes e durante do tratamento de colo, para clareamento das discromias e suavização das rugas da paciente $n^{\circ} 2$

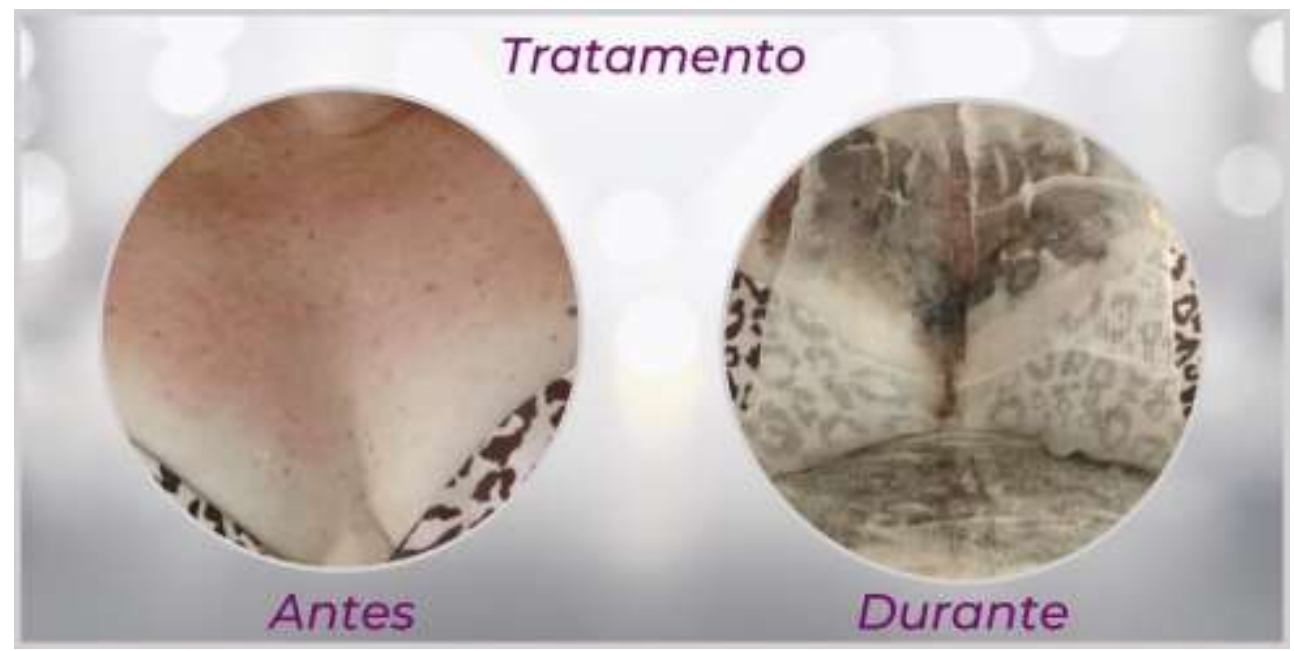

Fonte: da autora (2020).

Após a finalização foi registrado os resultados após 5 e 40 dias, conforme Figura 4.

Figura 4 - Fotos do acompanhamento da descamação da paciente $\mathrm{n}^{\circ} 2$ 


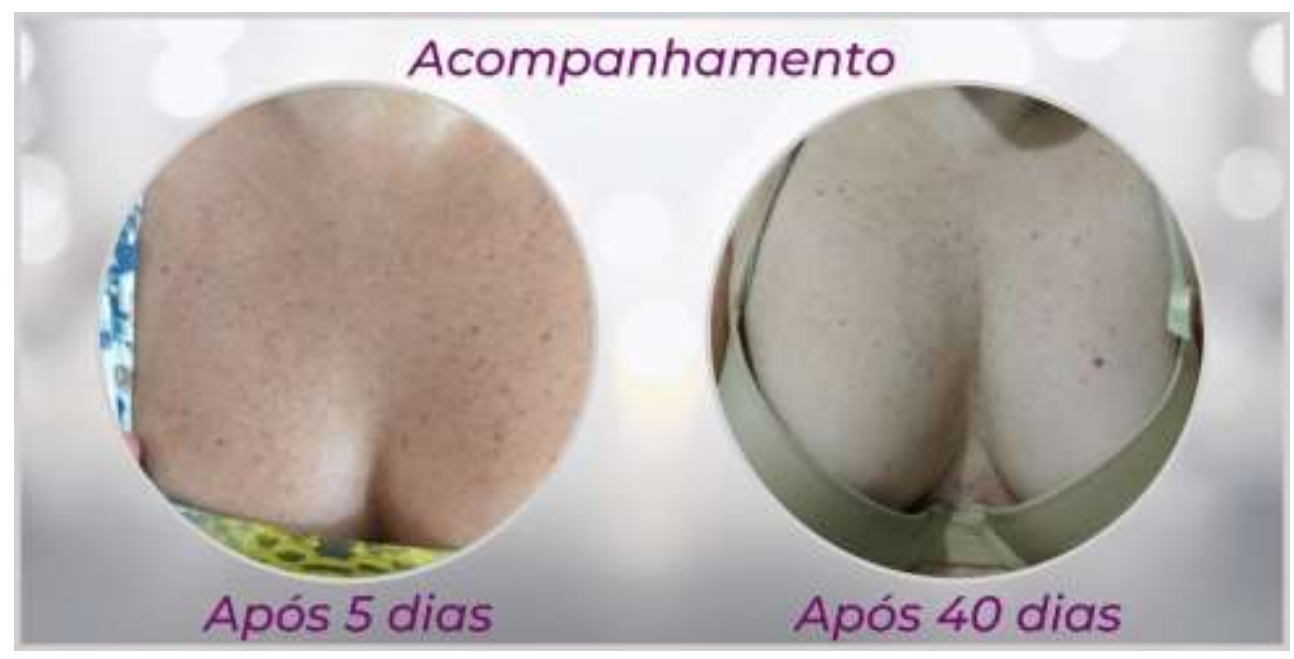

Fonte: da autora (2020).

A foto da descamação foi tirada após 5 dias do tratamento e a foto do depois foi tirada 40 dias após todo o tratamento, vide Figura 4. Protocolo: Peeling Orgânico e Mescla de Ativos com a técnica de sangria sendo: microagulhamento $2 \mathrm{~mm}$, na $1^{\mathrm{a}}$ sessão, dermapen na $2^{\mathrm{a}}$ sessão, ventosaterapia e eletropuntura na $3^{\mathrm{a}}$ sessão, em todas as sessões Peeling Orgânico.

$\mathrm{Na}$ avaliação geral das fotografias iniciais e após o término do estudo, os tratamentos realizados com mescla de ativos clinicamente, complementada pelo uso home do Serum Vitamina E, A.Hialurônico, apresentou melhora na ptose, porém observa-se que o tratamento do peeling orgânico, em conjunto com a técnica de sangria e suas mesclas de ativos, complementada pelo uso home care mostra-se mais efetiva para ptose, discromias, tecido mais liso sem discromias.

Esta observação é bem caracterizada nas fotografias vide Figura 4, comparando-se com os demais. Nas imagens observa-se que houve uma dispersão dos grânulos de melanina após o período de tratamento, porem estes apresentam-se fragmentados mais intensamente na região do colo, onde foi utilizado peeling orgânico com cataplasma, seguido deaplicações das técnicas de sangria e mesclas de ativos.

No final do estudo os pacientes notaram despigmentação, melhora da ptose, relataram ser um tratamento suportável e não levar muito tempo para ser realizado. Os resultados agradaram os mesmos, que mostraram interesse em dar continuidade ao tratamento com esta combinação de protocolos e confirmam que um rosto com expressão mais harmoniosa melhora seu convívio social. 


\section{CONCLUSÃO}

Nas condições experimentais deste estudo, foi possível concluir que entre os 2 pacientes com presença de hiperpigmentação e envelhecimento da pele, que atenderam aos critérios de inclusão do estudo e que se submeteram ao protocolo proposto clinicamente e home care durante cinco semanas, todos terminaram o estudo. Eles seguiram corretamente as orientações de uso da formulação home care; sendo o protocolo proposto bem tolerado e sem efeitos adversos.

Os resultados obtidos através de registros fotográficos mostram que a associação de peeling orgânico com as mesclas de ativos na técnica de Sangria, complementado com o uso home care, proporcionou um melhor clareamento e rejuvenescimento do tecido, em comparação com o resultado obtido no protocolo adotado somente com as mesclas ativas, Peeling Orgânico e home care. O grau de satisfação dos voluntários com o resultado do protocolo adotado envolve diminuição da pigmentação contribuindo com o aumento de sua autoestima e bem estar.

\subsection{Sugestão para Pesquisas futuras}

Para trabalhos futuros sugere-se ampliar o número de pacientes, o tempo de duração do protocolo e inclusão de outras técnicas de sangria para efeitos comparativos e obtenção de resultados mais conclusivos.

\section{REFERÊNCIAS}

BARCELOS, Yasmin Mendes Reis; FERREIRA, Keila Suzzete. Estudo dos efeitos dos peeling de alfa hidroxiácidos para o rejuvenescimento da pele. 2018. Trabalho de Conclusão de Curso. Disponível em: https://unifasc.edu.br/wp- content/uploads/2019/07/ARTIGO-Yasmincorrigido.pdf. Acesso em: 15 Nov. 2019.

SILVA, Danielle Ísis de Sá e. Utilização da técnica de intradermoterapia para rejuvenescimento facial. Recife, 2018. Monografia (Pós Graduação Latu Sensu em Biomedicina Estética) - Centro de Capacitação Educacional - Cce. Disponível em: https://www.ccecursos.com.br/img/resumos/biomedicina-estetica/tcc- -danielle-issis-de-s--e- silva.pdf. Acesso em: 16 Dez. 2019.

\section{ANEXO A - TERMO DE CIÊNCIA}


Estudo comparativo do tratamento de peeling orgânico com mesclas de ativos e técnicas de sangria, utilizando ativos cosméticos e home care. Você está sendo convidado a participar deste estudo que tem por objetivo tratar o envelhecimento tecidual, comparando os resultados das mesclas de ativos e técnicas de sangria, isolado e associados ao uso de Peeling Orgânico. O documento abaixo contém todas as informações relevantes sobre a condução deste estudo.

Após a assinatura deste termo, você será questionado sobre informações que contemplam seus dados pessoais, cuidados cosméticos que utiliza e histórico médico. Se não houver nenhuma limitação à sua participação neste estudo, será realizado um teste para verificar sua sensibilidade aos produtos utilizados. Uma pequena quantidade de cada produto será aplicada pela autora deste estudo, na face interna de seu braço no dia que antecede o início do estudo. No dia seguinte, pela manhã você deverá se dirigir até a Clínica de estética onde a pesquisadora irá observar o local para quantificar a resposta. Você só seguirá com a pesquisa caso não apresente qualquer reação de sensibilidade ou irritação. Você deverá comparecer ao local do estudo uma vez por semana, em horários pré- agendados, com disponibilidade de 30 a 50 minutos para a aplicação do protocolo e acompanhamento.

O protocolo clínico consiste em higienização da área a ser tratada, com sabonete neutro e remoção com algodão embebido em água seguido de secagem suave.

A aplicação do produto será em movimentos suaves circulares, sendo aplicado a solução de peeling orgânico, seguida das mesclas com e sem técnica de sangria.

Os produtos home care deverão ser aplicados a noite, removidos na manhã seguinte com a lavagem da área tratada, utilizando sabonete líquido neutro e água corrente, secando suavemente. Em seguida uso do FPS 30. É importante que seja suspendido o uso de qualquer outro produto durante o estudo. Será disponibilizado a você um sabonete líquido para a higienização, Serum e FPS 30. Ao final do período do estudo, serão realizados novamente registros fotográficos da área tratada, para avaliar se houve uma evolução no rejuvenescimento e discromias e comparar a eficácia dos ativos que serão utilizados.

Pode ocorrer descamação na região devido à utilização do Peeling e durante o procedimento de sangria pode sentir um desconforto momentâneo.

Se surgirem riscos durante a aplicação do protocolo, desaparecerão com a interrupção 
imediata do uso. Em casos de reações não retrocederem naturalmente com a interrupção do uso, você deverá contactar a pesquisadora e serão subsidiados os custos de consultas médicas e tratamento. A utilização deste protocolo proposto pode suavizar as rugas, harmonizar o contorno facial e clarear as manchas solares, senis ou eliminá-las, resultando em um aumento da autoestima.

O estudo será realizado na Clínica Studio 2E, na cidade Mairiporã, São Paulo, SP.

\section{DESISTÊNCIA DA PARTICIPAÇÃO DO ESTUDO}

A participação deste estudo é voluntária, quem não quiser fazer parte do mesmo está livre, assim como quem concordar em participar do estudo e mudar de ideia no decorrer do mesmo, está livre para a desistência. Mediante qualquer intercorrência durante o período de participação na pesquisa o participante terá a participação descontinuada. Os registros fotográficos serão utilizados apenas para fins científicos como semanas acadêmicas e publicações em revistas e artigos. Se desejar, você poderá tomar conhecimento dos resultados desta pesquisa.

Gostaria de ser comunicado quanto aos resultados desta pesquisa?

( ) Sim, gostaria. ( ) Não gostaria.

Será necessário utilizar os registros fotográficos para esta divulgação. Você permite a utilização dos registros fotográficos para divulgação dos resultados desta pesquisa?

( ) Sim. ( ) Não.

Você não receberá nenhum tipo de pagamento, do mesmo modo que não terão nenhum custo relacionado aos procedimentos. As informações fornecidas pelos voluntários e os testes realizados serão confidenciais, somente quem terá conhecimento serão as pessoas envolvidas no estudo. Os questionários serão identificados através de um código (número de protocolo, seguido de uma letra) criado na entrada do estudo, que será a única identificação utilizada no banco de dados do estudo, utilizado para análise e divulgação no meio científico.

Os registros fotográficos serão divulgados somente com a autorização explícita do responsável.

\section{PERGUNTAS E DÚVIDAS RELACIONADAS AO ESTUDO}

Se houver alguma dúvida estas serão esclarecidas pela autora do estudo, acadêmica pós graduanda em Biomedicina Estética, Daniela Lopez, pelo telefone (11) 947315077 a 
qualquer momento.

Mairiporã, de de 2019.

Assinatura da pesquisadora / autora

Observação: o presente documento, baseado no item IV das diretrizes e normas regulamentadoras para pesquisa em saúde, do conselho Nacional de Saúde (Resolução 466/12), será assinado em duas vias, de igual teor, ficando uma via em poder do voluntário e outra com a pesquisadora responsável.

\section{ANEXO B - QUESTIONÁRIO DE AVALIAÇÃO DO VOLUNTÁRIO}

Data: Protocolon:

Dados Pessoais:

Nome: $\quad$ Idade:

Data de Nascimento: / / Estado civil:

Endereço:

CEP:

Bairro:

Cidade: Telefone celular:

Residencial: Profissão:

Dados para seleção:

1. $\quad$ Apresenta hiperpigmentação ? Sim ( ) Não ( )

2. Fototipo (classificação de Fitzpatrick): I ( ) II ( ) III ( ) IV ( ) V ( ) VI ( )

3. Usa algum produto na pele? Qual?

4. Apresenta reações alérgicas ou hipersensibilidade a algum medicamento ou cosmético? Você está grávida ou amamentando? Sim ) Não ( )

5. Você tem alguma doença crônica? Qual?

6. Você tem alguma doença de pele? Sim ( ) Não ( )

7. Possui algum implante metálico? Sim ( ) Não ( )

8. Possui marcapasso? Sim ( ) Não ( )

9. Tem epilepsia? Sim ( ) Não ( ) 
10. Você tem algum tipo de distúrbio mental? Sim ( ) Não ( )

11. Você aceitaria fazer uso de um tratamento único, não utilizando nenhum outro tipo de produto que não seja o proposto? Sim ( ) Não ( )

12. Você está realizando algum tipo de tratamento médico? Sim ( ) Não ( ) Quais as medicações?

\section{Histórico e Hábitos de vida:}

13. Em que idade surgiram as manchas?

14. É fumante? Sim ( ) Não ( ). É etilista? Sim ( ) Não ( )

15. Gestações ? Em que idades: / / /

16. Faz uso de anticoncepcional oral? Sim ( ) Não ( ) Qual?

17. Desde quando?

18. Já realizou algum tratamento para a hiperpigmentação? Qual?

19. Há quanto tempo? que produtos usou?

20. Você avalia o grau de pigmentação da sua pele como: ( ) Pigmentada ( ) Muito pigmentada( ) Pouco pigmentada

21. Você avalia o grau de envelhecimento da sua pele como: ( ) cansada ( ) pouco envelhecida ( ) Muito envelhecida

\section{Anexo C - Questionário de satisfação}

O que você achou do resultado no clareamento das manchas?

( ) Regular ( ) Bom ( ) Muito Bom ( ) Ótimo

Qual sua opinião quanto à dor no procedimento?

( ) Regular ( ) Bom ( ) Muito Bom ( ) Ótimo

O que você achou quanto ao tempo de aplicação do procedimento?

( ) Regular ( ) Bom ( ) Muito Bom ( ) Ótimo

Você indicaria este tratamento?

( ) Sim ( ) Não

Em relação a sua vida social acredita que o tratamento melhorou seu convívio?

( ) $\operatorname{Sim}($ ) Não

Seus amigos e familiares notaram alguma diferença na sua pele?

( ) $\operatorname{Sim}$ ( ) Não

O que você achou do resultado no rejuvenescimento? 
( ) Regular ( ) Bom ( ) Muito Bom ( ) Ótimo 